\title{
Research on Aesthetic Training of University Students in Dancesport Teaching
}

\author{
Xin Weng, Qianwen Zheng, Xianlou Wu, Bin Wang*, Leijie Gong \\ School of Physical Education and Health Science, Zhejiang Normal University, Jinhua, China \\ Email: ^1850854598@qq.com
}

How to cite this paper: Weng, X., Zheng, Q.W., Wu, X.L., Wang, B. and Gong, L.J. (2021) Research on Aesthetic Training of University Students in Dancesport Teaching. Open Access Library Journal, 8: e7538. https://doi.org/10.4236/oalib.1107538

Received: May 18, 2021

Accepted: June 14, 2021

Published: June 17, 2021

Copyright $\odot 2021$ by author(s) and Open Access Library Inc.

This work is licensed under the Creative

Commons Attribution International

License (CC BY 4.0).

http://creativecommons.org/licenses/by/4.0/

(c) (i) Open Access

\begin{abstract}
College sports dance course teaching is a valuable course for students and society. This paper focused on the aesthetic training of university students in dancesport teaching. It introduced four aesthetic feelings in the teaching of sports dance, analyzed the status quo of aesthetic training, and proposed the training methods such as strengthing basic education, improving and standardizing education, and choosing the right music.
\end{abstract}

\section{Subject Areas}

Physical Education

Keywords

College Sports, Dance Teaching, Aesthetic Training

\section{Introduction}

In western countries, dancesport is regarded as a kind of eternal art. The constant updating of ballroom dance traditions reflects the environment of The Times and has become a medium for communication and emotional education. College sports dance course teaching is a valuable course for students and society. Therefore, it has special artistic value in the implementation of teaching and can promote the improvement of educational quality in all fields. The development of the sports dance course, to student's body physique, has a very important influence, but also can make the students keep a good mood, also can make the students' aesthetic enhancement, no matter what kind of dance, also don't need how strong feeling and rhythm, as long as it is the beautiful music of students can accept, can meet the conditions of sports dance teaching. The aesthetic significance of sports dance is reflected in four main fields. 


\section{Four Aesthetic Feelings in the Teaching of Sports Dance}

\subsection{Aesthetic Feeling of Movement}

Latin dance and modern dance are two important dance fields. Unlike other types of dance, the technical movements are very strict in different areas of dance, so the dancer's movements are very strict. In university sports dance class, the students learning sports dance, the goal is to master the most basic dance, able to master the basic movements and actions at the same time, improve the overall aesthetic Angle, let one's own body and dance level be able to get training and promotion, in the process of sports dance teaching, in addition to the grasp of the basic dance movements, students also take the constant challenges and try new dance moves, make the entire sports dance looks more harmonious and beautiful [1].

\subsection{Aesthetic Feeling of Music}

Without music, there would be no dancing, no training and no performance. Just like sports dance, it cannot be separated from music, so music is the soul of any dance. The melody, rhythm, melody, and emotional expression of music can bring a lot of changes to the final performance of dance. The beauty of sports dance is closely related to music. To truly understand the beauty of dance sports, we must understand and apply the beauty of music to make dance sports more attractive to the audience and create a better environment for the audience to immerse in the beauty.

\subsection{Aesthetic Feeling of Physical Beauty}

Sports dance itself is a kind of dance, the natural beauty of sports dance also needs the foundation of dance, shape plays an important role in the beauty of sports dance, only good image and enthusiasm can let the dancer show good image and enthusiasm. In the dance class, we must pay special attention to the students' physical exercise. This is also an important manifestation of students' physical progress and an important goal of dance class teaching.

\subsection{Aesthetic Feeling of Clothing}

The beauty of clothes changes over time, which indicates that aesthetic ideas are constantly updated. After all, clothes are practical and should be consistent with the human body, not separated from it. The material and lines of clothes should be consistent with the human body.

\section{Status Quo of Aesthetic Training}

\subsection{Insufficient Attention}

Many college teachers fail to realize the importance of aesthetic education. They will spend most of their time and talent on sports standardization and technical training. Therefore, in practice, many students dominate in all aspects of sports, 
but in fact, the combination of strict behavior and bad mood does not make them feel beautiful. Therefore, teachers must return to the essence of dance sports teaching and pay attention to the educational content.

\subsection{Limitations}

The types of teachers and teaching methods directly affect the results of physical education. Today, many teachers use traditional concepts and methods. Teachers introduce physical education to students, and students imitate the behavior of teachers. This teaching method is relatively simple, but it does not meet the needs of improving the education level. Teachers do not understand each student's understanding, nor do they adopt appropriate methods for students to learn sports dance independently, nor do students understand the true meaning of sports dance.

\subsection{The Methods Are Not Scientific}

In order to ensure that students receive effective aesthetic education, teachers must distinguish dynamic education from aesthetic education [2]. The emphasis of teacher training is to master technical activities. Flexible dance centered on student movement helps students to listen to movement and dance in teaching. Teachers actively study students' teaching and feel the aesthetic influence of movement.

\section{Training Methods}

\subsection{Strengthening Basic Education}

In the teaching of dance sports, it is necessary to improve the mastery of basic skills to enable students to acquire greater aesthetic ability, and the development of the same basic skills is the basis of aesthetic education. Teachers must strengthen their attitude towards their students. In order to get better grades, teachers must have a clear understanding of sports dance or each student's understanding, and adapt to local conditions to avoid conflicts between students' education, while teachers can make wonderful music. This will give students the opportunity to learn more dance sports [3].

\subsection{Improving and Standardizing Education}

First of all, in order for students to better understand, teachers must break the past consistent behavior and standard role. Some sports are difficult, so teachers have to introduce more things into teaching and introduce students in different ways. Secondly, teachers must show correct actions and ideas to students in the teaching process. In addition to the traditional technical movement, the teacher must also ensure the consistency of the movement and provide the students with language explanations to show them the beauty of the dance in a way that is easier to understand. 


\subsection{Choosing Right Music}

The right music can make the dance more attractive, but it can also provide the audience with more sensory stimulation, so that both parties can feel the temptation and emotional expression of the movement and dance. Music is the soul of dance, should choose a kind of music, style can be all of the students' ability to manage because everyone's advantage is different, therefore, inappropriate concert let them lose interest in learning, to meet them in time in math, science, and aesthetic aspects of the special demand, so as to give full play to them in the role of emotional expression, teaching method and restrictive.

\section{Conclusion}

At present, sports dance is an important part of the college curriculum, which can improve students' physical education and artistic quality, so as to improve their aesthetic quality and ability. In addition to cultivating students' ability, we should also let them develop a strong sense of beauty, improve students' aesthetic ability, and constantly strengthen it. If we want students to discover the beauty of dance in terms of aesthetic skills and innovations, as well as training mechanisms to enable students to participate in dance courses in a beautiful environment, we must take effective measures to provide comprehensive training, provide students with the means to strive for sports dance learning and increase their interest in learning.

\section{Conflicts of Interest}

The authors declare no conflicts of interest regarding the publication of this paper.

\section{References}

[1] Zhu, L.S. and Yuan, Y. (2018) Research on Aesthetic Training of Students in Sports Dance Teaching in Universities. Contemporary Sports Technology, 8, 38-39.

[2] Fu, Z.W. (2015) The Exploration for the Application of Question Teaching Method in the High School History Classroom. Master Thesis, Henan University, Henan, China.

[3] Fu, Y.F. (2019) Research on the Cultivation and Training Methods of Students' Aesthetic Feeling in College Sports Dance Teaching. Appreciation, 9, 304-305. 